\title{
APPLICATION AND RESULTS OF THE MANCHESTER SHORT ASSESSMENT OF QUALITY OF LIFE (MANSA)
}

\author{
S. PRIEBE, P. HUXLEY, S. KNIGHT \& S. EVANS
}

\begin{abstract}
BUMMAPY
Background Based on experiences and empirical evidence gained in studies using the Lancashire Quality of Life Profile (LQLP), the Manchester Short Assessment of Quality of Life (MANSA) has been developed as a condensed and slightly modified instrument for assessing quality of life. Its properties have been tested in a sample of community care patients.

Method Fifty-five randomly selected patients on the Care Programme Approach were interviewed using the LQLP, the MANSA and the Brief Psychiatric Rating Scale.

Resulfis Correlations between subjective quality of life scores on MANSA and LQLP were all 0.83 or higher ( 0.94 for the satisfaction mean score). Cronbach's alpha for satisfaction ratings was 0.74 , and association with psychopathology was in line with results for LQLP as reported in the literature.

Conclusions The MANSA is a brief instrument for assessing quality of life focusing on satisfaction with life as a whole and with life domains. Its psychometric properties appear satisfactory.
\end{abstract}

\section{HNTRODUCTHON}

In the last 10 years, quality of life in people with mental illness has become a popular construct and an important outcome criterion in evaluative research. Various instruments have been developed for measuring it. In most of them, satisfaction with life in general and with life domains plays a central role and is assessed on Likert type self rating scales (Orley et al. 1998).

Based on Lehman's original work in the US, Oliver et al. (1991/92) established the Lancashire Quality of Life Profile (LQLP) which has been widely used in Europe (Priebe et al. 1995; Oliver et al. 1997). Several research centres now have huge data bases, e.g. in Manchester, Berlin, London and Verona. In samples with severe mental illness, subjective quality of life ratings obtained by the LQLP have been shown to be sufficiently reliable (Kaiser \& Priebe, 1998), to have a discriminative ability between different samples and treatment settings (Heinze et al. 1997; Kaiser et al. 1997; Priebe et al. 1998a,b), and to be sensitive to change (Holloway \& Carson, 1998; Hoffmann et al. 1998; Priebe et al. in press a). Yet, research has also revealed some shortcomings of the LQLP: Overall, it takes approximately 30 minutes to administer what is too long for some purposes; some incorporated parts such as the affect-balance-scale assess mainly psychopathology which should be assessed by 
specific scales; most importantly, there are many items in the LQLP that have not been found to be relevant for discriminating between samples or for demonstrating change. Regarding the objective variables, there are various items with insufficient variance. In addition, there is no clear way to sum up single item scores for each domain nor has an overall score been established. Shortcomings of the subjective variables in the LQLP relate to inconsistency in the language used i.e. "how do you feel about ...?" versus "how satisfied are you with...?"; that the question about satisfaction with family is equivocal because it is unclear which part of the family is referred to while some life domains are assessed by one question and others by more than one question which complicates statistical analysis and interpretation of findings. Finally, it was widely felt that a question on the domain of sexual life is missing.

Based on experiences gained in several thousand quality of life interviews and on the results of systematic studies, we therefore developed the Manchester Short Assessment of Quality of Life (MANSA), a brief and modified version of the LQLP that has been intended to take into account all of the above mentioned shortcomings (see Appendix and Priebe et al. in press b). Objective questions that in previous studies have neither discriminated between settings or groups nor have been sensitive to change, were eliminated. Subjective questions were reduced to one item per life domain and put in a consistent language rating patients' satisfaction.

The MANSA consists of three sections:

(1) Personal details that are supposed to be consistent over time (date of birth, gender, ethnic origin, and diagnosis).

(2) Personal details that may potentially vary over time and have to be re-documented if change has occurred (education; employment status including kind of occupation and working hours per week; monthly income; state benefits; living situation including number of children, people the patient lives with, and type of residence).

(3) Only 16 questions are to be asked every time the instrument is applied. Four of these questions are termed objective and to be answered with yes or no. Twelve questions are strictly subjective. The objective items assess the existence of a "close friend", number of contacts with friends per week, accusation of a crime and victimisation of physical violence. The subjective questions obtain satisfaction with life as a whole, job (or sheltered employment, or training/education, or unemployment/retirement), financial situation, number and quality of friendships, leisure activities, accommodation, personal safety, people that the patient lives with (or living alone), sex life, relationship with family, physical health, and mental health. A manual outlines explanation of questions and their operationalisation (also see Priebe et al. in press b). Like in the LQLP, satisfaction is rated on 7-point rating scales $(1$ = negative extreme, 7 = positive extreme).

In a sample of community care patients we applied the MANSA and examined correlations with LQLP scores and with psychopathology.

\section{METHOD}

Data was collected within a review of the Care Programme Approach and care management by the School of Psychiatry at the University of Manchester. Local authorities were asked to select at random approximately 20 patients aged between 18 and 65 who are on the Care 
Programme Approach and receiving services under the Community and Mental Health legislation. For the purpose of this study, quality of life was assessed in all patients who were interviewed in three localities, i.e. two inner city and one metropolitan borough using the LQLP as well as the MANSA. Psychopathology was assessed on the 24 item version of the Brief Psychiatric Rating Scale (BPRS; Ventura et al. 1993). All interviews were done by one experienced researcher who was not involved in the patients' care.

\section{RESULTS}

Fifty-five patients ( 19 women, 36 men) were interviewed. Mean ( \pm s.d.) age of patients was $40.9 \pm 14.9$ years. The diagnosis was schizophrenia in 38 patients, bipolar-affective psychosis in 8 patients, first or recurrent episode of depression in 6 patients, obsessive compulsive disorder in 2 patients, and anxiety disorder in 1 patient. Mean BPRS total score was $33.4 \pm 7.4$. Twenty patients were from ethnic minorities. One patient was employed, 47 unemployed and 7 retired. Administration of the MANSA took between 3 and 5 minutes.

In the MANSA, 33 patients said they did not have "a close friend", and 39 had not visited or been visited by a friend within the last week. Two patients each reported having been accused of a crime or having been victims of physical violence within the last year.

Means of single satisfaction scores varied between $4.09 \pm 1.17$ (life as a whole today) and $5.18 \pm 0.82$ (family). The mean score of all satisfaction items was $4.56 \pm 0.51$. Table 1 shows Pearson's correlations between satisfaction ratings in the MANSA and the LQLP.

All coefficients are above 0.82 , including those regarding domains that are assessed by two or more items in the LQLP and by only one in the MANSA.

Correlations of MANSA subjective quality of life mean score with BPRS total score was $r=-0.49 \quad(p<0.001)$ and with the BPRS sub score anxiety/depression $r=-0.42$ $(p<0.01)$. Cronbach's alpha for the satisfaction ratings in MANSA was 0.74 .

Table 1

Correlations between satisfaction ratings on LQZ $\mathbb{P}$ and WAN MA

\begin{tabular}{lc}
\hline Satisfaction with & Pearson's r* $^{*}$ \\
\hline Life as a whole & .99 \\
Job/unemployment/retirement & .94 \\
Finances $^{1}$ & .94 \\
Friendships $^{1}$ & .94 \\
Leisure activities $^{1}$ & .83 \\
Accommodation $^{2}$ & .83 \\
Safety $^{1}$ & .85 \\
Physical health $^{\text {Mental health }}$ & .93 \\
Mean score & .94 \\
\hline
\end{tabular}

${ }^{1}$ mean of two items in LQLP, ${ }^{2}$ mean of six items in LQLP, ${ }^{*} \mathrm{p}=<0.001$ for each correlation 


\section{DISCUSSHON}

The high correlations of MANSA and LQLP scores suggest a concurrent validity for the MANSA in addition to a face and construct validity. Internal consistency of satisfaction ratings seems reasonable, and associations with psychopathology are in line with results for the LQLP reported in the literature (Kaiser et al. 1997; Priebe et al. 1998a,b). Thus, the MANSA appears a viable and valid instrument to obtain condensed and accurate quality of life data, and it is brief enough to be included in a minimum data set.

It should be taken into account, however, that the MANSA shares conceptual and methodological limitations with the LQLP and other similar instruments. Although it assesses some objective indicators of quality of life, its focus is clearly on subjective ratings. The underlying concept of quality of life is a generic and not a disease specific one. All questions allow comparisons with the general population, and are not specifically illness or symptom related. If in research or routine evaluation the interest is in more specific symptom-related measures, other scales should be used in addition to or instead of the MANSA. The same holds true if other related but nevertheless distinct constructs such as social functioning are to be assessed.

In evaluative studies, psychopathology should be assessed and controlled for as an influential factor. Mean satisfaction scores may serve as a non-specific outcome criterion. Satisfaction ratings with single life domains should be used for testing domain specific and a priori stated hypotheses, and for generating such hypotheses if mean scores reveal significant differences.

$\triangle P B P A N D X$

Manchester Short Assessment of Quality of Life (MANSA)

Section 1

Date of birth ; Gender_; Ethnic origin __; Diagnosis

Section 2

In a first interview, ask all questions 1 to 9 . In a repeat interview, ask first, whether there have been any changes in the respondent's circumstances. If the answer is yes, complete questions 1 to 9 . If the answer is no, go straight to section 3 (question 10).

1) Age at leaving full time education

2) Employment status

If employed, ask questions 3 and 4 , otherwise ask question 5

3) What is your occupation?......

4) How many hours a week do you work?

5) What is your total monthly income after tax?

6) Which if any state benefits do you receive?

7) How many children (if any) do you have?

8) Who else (if anybody) do you live with?

9) In which type of residence do you currently live?

Section 3

10) How satisfied are you with your life as a whole today?*

11) How satisfied are you with your job (or sheltered employment, or training/education as your main occupation)?*

Or if unemployed or retired, how satisfied are you with being unemployed/retired?*

12) How satisfied are you with your financial situation?*: 
13) Do you have anyone who you would call a "close friend"? Yes/No

14) In the last week have you seen a friend? (visited a friend, been visited by a friend or met a friend outside both your home and work)? Yes/No

15) How satisfied are you with the number and quality of your friendships?*

16) How satisfied are you with your leisure activities?*

17) How satisfied are you with your accommodation?*

18) In the past year have you been accused of a crime? Yes/No

19) In the past year have you been a victim of physical violence? Yes/No

20) How satisfied are you with your personal safety?*

21) How satisfied are you with the people that you live with?*

Or if you live alone, how satisfied are you with living alone?*

22) How satisfied are you with your sex life?*

23) How satisfied are you with your relationship with your family?*

24) How satisfied are you with your health?*

25) How satisfied are you with your mental health?*

*use the Satisfaction Scale below

\begin{tabular}{|c|c|c|c|c|c|c|}
\hline \multicolumn{7}{|c|}{ Satisfaction Scale } \\
\hline $\begin{array}{c}1 \\
\text { Couldn't } \\
\text { be worse }\end{array}$ & $\begin{array}{c}2 \\
\text { Displeased }\end{array}$ & $\begin{array}{c}3 \\
\text { Mostly } \\
\text { Dissatisfied }\end{array}$ & $\begin{array}{c}4 \\
\text { Mixed }\end{array}$ & $\begin{array}{c}5 \\
\text { Mostly } \\
\text { satisfied }\end{array}$ & $\begin{array}{c}6 \\
\text { Pleased }\end{array}$ & $\begin{array}{c}7 \\
\text { Couldn't } \\
\text { be better }\end{array}$ \\
\hline
\end{tabular}

\section{REFERENCES}

HEINZE, M., TAYLOR, R., PRIEBE, S. \& THORNICROFT, G. (1997) The quality of life of patients with paranoid schizophrenia in London and Berlin. Social Psychiatry and Psychiatric Epidemiology, 32, 292-297.

HOFFMANN, K., KAISER, W., ISERMANN, M. \& PRIEBE, S. (1998) Changes in quality of life in long-term hospitalised psychiatric patients after discharge. (In German). Gesundheitswesen, 60, 232-238.

HOLLOWAY, F. \& CARSON, J. (1998) Intensive case management for the severely mentally ill. British Journal of Psychiatry, 172, 19-22.

KAISER, W., PRIEBE, S., BARR, W., HOFFMANN, K., ISERMANN, M., RÖDER-WANNER, U.-U. \& HUXLEY, P. (1997) Profiles of subjective quality of life in schizophrenic in- and out-patient samples. Psychiatric Research, 66, 153-166.

KAISER, W. \& PRIEBE, S. (1998) On the measurement of long-term and short-term change of subjective quality of life in chronic schizophrenia patients. (In German). Nervenarzt, $699,219-227$.

OLIVER, J.P.J., HUXLEY, P.J., PRIEBE, S. \& KAISER, W. (1997) Measuring the quality of life of severely mentally ill people using the Lancashire Quality of Life Profile. Social Psychiatry and Psychiatric Epidemiol. ogy, 32, 76-83.

OLIVER, J.P.J. (1991-92) The social care directive: Development of a quality of life profile for use in community services for the mentally ill. Social Work \& Social Sciences Review, 3, 5-45.

ORLEY, J., SAXENA, S. \& HERRMANN, H. (1998) Quality of life and mental illness. British Journal of Psychiatry, 172, 291-293.

PRIEBE, S., GRUYTERS, T., HEINZE, M., HOFFMANN, C. \& JÄKEL, A. (1995) Subjective criteria for evaluation of psychiatric care - Methods for assessment in research and routine care. (In German). Psychiatrische Praxis, 22, 140-144.

PRIEBE, S., WARNER, R., HYBSCHMID, T. \& ECKLE, I. (1998a) Employment, attitudes to work and quality of life among people with schizophrenia in three countries. Schizophrenia Bulletin, 24, 469-477.

PRIEBE, S., KAISER, W., HUXLEY, P.J., RÖDER-WANNER, U.-U. \& RUDOLF, H. (1998b) Do different subjective evaluation criteria reflect different constructs? Journal of Nervous and Mental Disease, 186 , $385-392$.

PRIEBE, S., RÖDER-WANNER, U.-U. \& KAISER, W. (in press a) Quality of Life in first admitted schizophrenia patients. Psychological Medicine. 
PRIEBE, S., HUXLEY, P., KNIGHT, S. \& EVANS, S. (in press b) The Manchester Short Assessment of Quality of Life (MANSA). In Priebe, S., Oliver, J. \& Kaiser, W. Quality of Life and Mental Health Care. Wrightson Biomedical Publ., Petersfield, UK.

VENTURA, J., LUKOFF, D., NUECHTERLEIN, K.H., LIBERMAN, R.P., GREEN, M.F. \& SHANER, A. (1993) Training and Quality Assurance with the BPRS Brief Psychiatric Rating Scales (BPRS): Expanded Version (4.0). International Journal of Methods in Psychiatric Research, 3, 227-243.

Professor Stefan Priebe, Department of Psychiatry, St. Bartholomew's and the Royal London School of Medicine and Dentistry, Queen Mary \& Westfield College, University of London, UK

Professor Peter Huxley, The Department of Psychiatric Social Work, School of Psychiatry and Behavioural Sciences, University of Manchester, UK

Susan Knight, The Department of Psychiatric Social Work, School of Psychiatry and Behavioural Sciences, University of Manchester, UK

Sherrill Evans, The Department of Psychiatric Social Work, School of Psychiatry and Behavioural Seiences, University of Manchester, UK

Correspondence to Professor Priebe, Academic Unit for Social \& Community Psychiatry, East Ham Memorial Hospital, London, E7 8QR, UK 